\title{
Distributed fibre-optic sensing applications at the Semmering Base Tunnel, Austria
}

Werner Lienhart BEng, MSc, PhD

Professor, Institute of Engineering Geodesy and Measurement Systems, Graz University of Technology, Graz, Austria (Orcid:0000-0002-2523-4052) (corresponding author: werner.lienhart@tugraz.at)

Fabian Buchmayer BSC, MSC

Project Assistant, Institute of Engineering Geodesy and Measurement

Systems, Graz University of Technology, Graz, Austria
Ferdinand Klug BSC, MSC

Project Assistant, Institute of Engineering Geodesy and Measurement

Systems, Graz University of Technology, Graz, Austria

Christoph Martin Monsberger BSC, MSC

University Assistant, Institute of Engineering Geodesy and Measurement Systems, Graz University of Technology, Graz, Austria

The Semmering Base Tunnel in Austria is currently one of the largest tunnel construction sites in Central Europe. Two tunnel tubes, each $27.3 \mathrm{~km}$ long, are being built from the portal and three intermediate construction sites. Each access point poses specific challenges, and structural monitoring is a crucial element to ensure both economic and safe construction. In this paper, the authors describe one of the most comprehensive distributed fibre-optic sensing installations on a tunnel construction site worldwide. At the Semmering Base Tunnel, fibre-optic sensing is used at every construction location to monitor tunnel linings, shafts, reinforced earth structures and pipelines. The authors also discuss the challenges posed by the installations and the results of long-term monitoring programmes. The installed monitoring systems will, furthermore, be used throughout the expected 150-year operational lifetime of the tunnel. Unlike conventional sensors, fibre-optic sensors do not comprise electric or moveable components at the measurement location. A longer lifetime can, therefore, be expected for fibre-optic sensors, which makes them promising candidates for condition-based maintenance of civil infrastructure.

\section{Introduction}

The Semmering Base Tunnel (SBT) is currently one of the main infrastructure projects in Austria. Two parallel $27.3 \mathrm{~km}$ tunnel tubes are being constructed between the town of Mürzzuschlag and the village of Gloggnitz. At present, all trains must cross the mountain ridge on the 165-year-old Semmering railway, comprising several short tunnels, viaducts, large height gradients and small curvature radii. Due to this historic track layout, the train speed is low and only short freight trains with two engines can pass the mountain. The base tunnel will reduce the train journey time between Austria's capital Vienna and its second largest town Graz from $2 \mathrm{~h} 35 \mathrm{~min}$ to $1 \mathrm{~h} 50 \mathrm{~min}$, which is a reduction of $30 \%$. Rail goods traffic capacity will, moreover, be considerably increased because the low height gradient will enable deployment of long freight trains with only one engine

To reduce construction time, the tunnel is being driven from the portal at Gloggnitz and from three intermediate construction access points in Göstritz, Fröschnitzgraben and Grautschenhof (Figure 1). Each construction site poses specific construction challenges, which are discussed in detail in the paper by Gobiet et al. (2017).

At the north portal and the Göstritz and Grautschenhof intermediate access points, conventional tunnelling based on the New Austrian Tunnelling Method (NATM) (OeGG, 2010) is being applied. At Fröschnitzgraben, the two tubes in the direction of Grautschenhof are also being constructed using NATM, whereas in the direction of Göstritz, two tunnel-boring machines (TBMs) are in use. As well as conventional geotechnical sensors, distributed fibre-optic sensing (DFOS) is being used at every construction site to increase worker safety, enable more efficient construction and assess the structural integrity of the tunnel during construction and over its expected 150-year operational lifetime.

\section{Distributed fibre-optic sensing}

\subsection{Background}

Fibre-optic sensors have evolved significantly in recent years and are well suited for the monitoring of large linear structures such as bridges, railway tracks, pipelines and tunnels. Modern DFOS systems can record strain, temperature changes and acoustic signals with high accuracy and high spatial resolution over several kilometres and, thereby, enable early detection of local defects, such as cracks and leakages. Monitoring of long-term strain development can, furthermore, be used to guide condition-based maintenance.

DFOS systems use the natural back reflection of an optical fibre. If light with a certain wavelength, usually around $1550 \mathrm{~nm}$, is coupled into an optical fibre, linear (Rayleigh) and non-linear backscatter effects (Brillouin and Raman) occur (Figure 2). Raman backscattering is solely temperature sensitive, whereas Rayleigh and Brillouin backscattering are also sensitive to strain. Brillouin instruments can capture measurements over very long ranges (up to several tenths of kilometres) with a typical spatial resolution of $0.5-2.0 \mathrm{~m}$, whereas Rayleigh strain instruments can measure only up to several tenths of metres but with a better spatial resolution in the range of a few millimetres. For more information about the principles of DFOS, see the book by Hartog (2018). This paper focuses on practical aspects and the achievable results in tunnelling applications. 


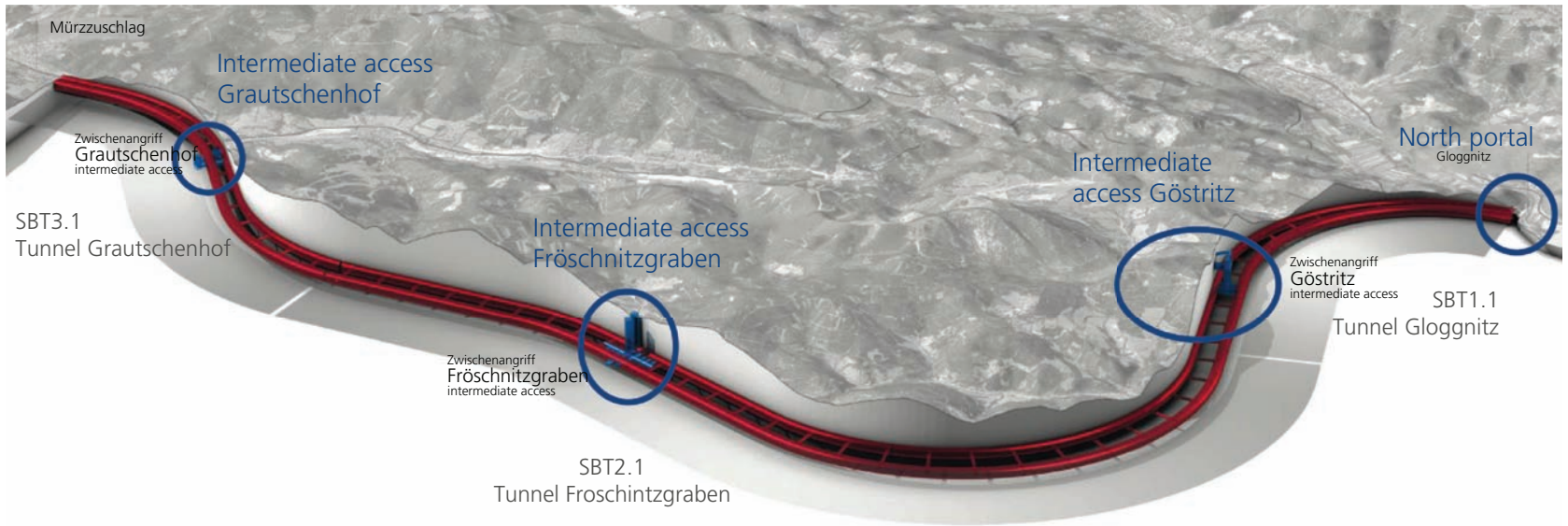

Figure 1. Schematic overview of construction sites of the SBT (after Gobiet et al., 2017)

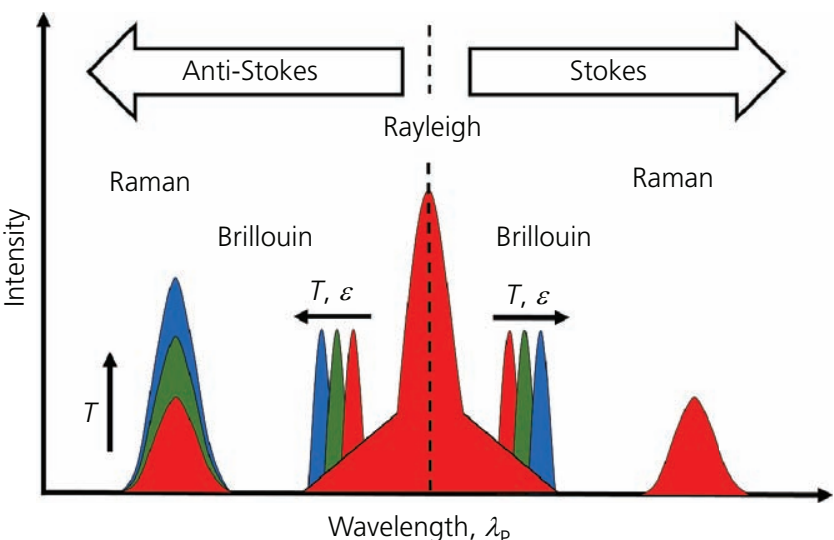

Figure 2. Backscattered spectrum changes induced by variable temperature and strain (after Krohn et al., 2014)

\subsection{Practical aspects of DFOS in tunnelling}

The fibre-optic sensing cables must, first and foremost, survive in the harsh tunnel construction environment. When, for instance, NATM is used, shotcrete is sprayed with a high pressure onto steel construction grids. The fibre-optic sensing cable must be able to withstand this pressure and possible grid vibration. Sensing cables that are directly embedded during construction, therefore, consist of several protective layers. These layers must, moreover, be interlocking to ensure reliable strain transfer from the surface of the cable to the core of the optical fibre. As already mentioned earlier, because Rayleigh and Brillouin backscattering signals are both strain- and temperature-sensitive, appropriate temperature compensation is crucial for reliable strain determination. A temperature-sensing cable with a loose and nontensioned fibre is often installed parallel to the strain-sensing cable with its rigid connection. If the spatial location of the two cables is known, the temperature-sensing cable readings can be used to correct numerically the impact of temperature on the strain-sensing cables. The corrected raw measurements, typically frequency shifts, must, lastly, be converted into strain readings, and the characteristic curve relating frequency shift to strain must therefore be known. This curve is approximately linear, but the slope coefficient differs between different cable types and sometimes also between different production batches of the same cable type, mandating individual calibration. An example of a cable calibration is provided in the paper by Monsberger et al. (2018a). All of these aspects had to be taken into account for the fibre-optic installations at the SBT as described in the following for each construction site.

\section{North portal Gloggnitz}

\subsection{Monitoring of a shotcrete tunnel lining}

The idea underlying NATM is that the tunnel cross-sections are cut out sequentially - that is, first the top heading followed by the bench and invert. Following excavation of each section, an outer primary lining is applied using shotcrete (also referred to as sprayed concrete), supported by anchors and steel arches. This outer lining is generally flexible and allows deformation to occur to some extent. Deformation evolution is usually assessed by daily manual measurements using a total station (OeGG, 2014). These measurements deliver the required information but are time consuming and thus performed only during the initial weeks following construction. Long-term terrain movements, erosion and recent tectonics could potentially change the equilibrium state of the mountain during the operational lifetime of the tunnel. To assess the long-term behaviour of the tunnel lining, new measurement techniques are evaluated at the SBT. Conventional methods, such as three-dimensional (3D) pointwise geodetic deformation measurements or laser scanning, are usually expensive and time-consuming and often require an interruption of tunnel traffic. DFOS, on the other hand, enables remote tunnel monitoring after installation. In order to verify the robustness and the suitability of DFOS for the monitoring of the shotcrete lining of a tunnel, several cross-sections of the SBT were equipped with sensing cables. 


\subsection{Installation in tunnel linings}

De Battista et al. (2015) reported the installation of DFOS cables between the first and second layers of the sprayed concrete lining. In their application, the sensing cable was clamped every $0.5 \mathrm{~m}$ to the surface of the primary lining. The authors, in contrast, embedded the sensing cables in both layers of the shotcrete lining, which, advantageously, allows both strain changes in the circumference direction and curvature changes to be derived.

For the authors' instrumentation, cables from Solifos AG (formerly Brugg AG) were used. In the installation of 2017, two BRUsens V3 cables were installed in one cross-section to measure strain and temperature. This cable has a structured surface that ensures rigid bonding with the concrete along the entire cable length. One section of the cable was directly mounted to the reinforcement grid, while the other one was loosely installed in a cladding tube to be sensitive only to temperature effects. In this installation, all measurements were retrieved with a fibre-optic instrument based on the Rayleigh principle with a spatial resolution of $1 \mathrm{~cm}$ (Monsberger et al., 2018a, 2018b).

Another installation was completed 1 year later in March 2018 in the second tunnel tube (Henzinger et al., 2018). One cable (BRUsens V3) was used to measure strain, and a different cable type (BRUsens) was used to measure temperature. Both cables use a metal tube as a protective layer. The optical fibre in the temperature cable is, however, also embedded in a gel, preventing strain transfer from the shotcrete to the fibre. This strain insensitivity was verified in laboratory tests during concrete beam load tests (Henzinger et al., 2018). Cables were first installed in the two concrete layers of the top heading. A few days later, the bench and invert were also excavated at this crosssection and sensing cables were again installed in both shotcrete layers. All cables were mounted directly on the reinforcement grids using cable ties (Figure 3).

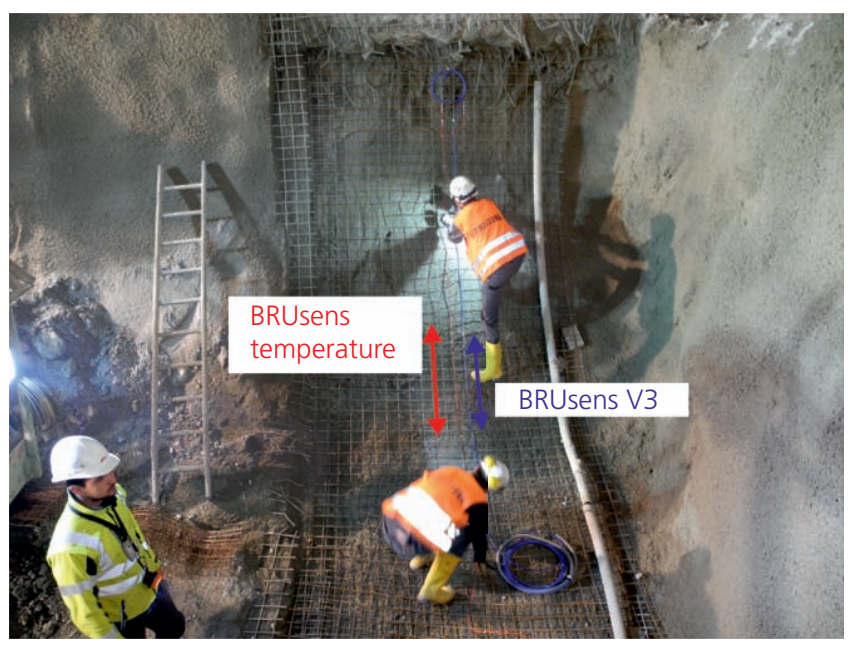

Figure 3. Installation of sensing cables on the reinforcement grid of the bench and invert
The spatial location of the cable in the tunnel coordinate system was then measured with a total station since knowledge of the exact location of the strain and temperature cables is crucial for reliable temperature compensation. The known 3D positions, furthermore, support data interpretation and comparison with other sensor data. To improve visualisation, 3D point clouds of the cross-section were obtained by 3D laser scanning. Figure 4 shows the geo-referenced point clouds and the measured cable positions.

Shotcrete was sprayed following cable installation and performance of a functionality test. Figure 5 shows this process for the top heading. Scanning was performed before and after application of the first shotcrete layer and following the application of the second layer. The actual thickness of the concrete layer can, hence, be determined from these 3D measurements.

\subsection{Fibre-optic measurements and results}

Fibre-optic measurements started immediately after installation, and the whole section was fully autonomously monitored with two measurements per hour for several weeks until the deformations decayed. The instrument was placed in a robust metal box about $100 \mathrm{~m}$ behind the measurement section. Following deformation stabilisation, epoch-wise measurements were performed at monthly intervals. As already mentioned in the measurement section of the first tube, a Rayleigh backscattering instrument from Luna was used, and for the installation in the second tube, a Brillouin instrument from fibrisTerre was used.

Figure 6(a) shows the spatial distribution of the strain along the outer shotcrete layer section at different times. The strain development at five selected locations is indicated in Figure 6(b). As expected, the strain development slows down after the first few days. However, it can be clearly seen that the excavation of the bench and invert initiated new deformations of already stabilised areas.

After the initial permanent measurement period, the epoch-wise measurements were continued. Figure 7 indicates that more than 1 year after installation, deformations are still progressing although at a much smaller rate. Overall, the results confirm that the selected construction parameters (round length of the excavation, thickness of shotcrete layer, number of anchors) were appropriate and thus were also used for the further construction in this tunnel section.

At both this cross-section and the fibre-optic cross-section of the first tube, the distributed fibre-optic measurement results are in good agreement with the results of other point sensors, for instance, fibre Bragg gratings (Henzinger et al., 2018) or vibrating wire sensors (Wagner et al., 2020) and total station measurements (Monsberger et al., 2018b). Unlike point sensors, distributed fibreoptic sensors inherently allow information to be captured along the entire fibre, leaving no blind spots and even enabling detection of local lining failure. This benefit is also a motivation for the monitoring installation at the Göstritz intermediate access point. 


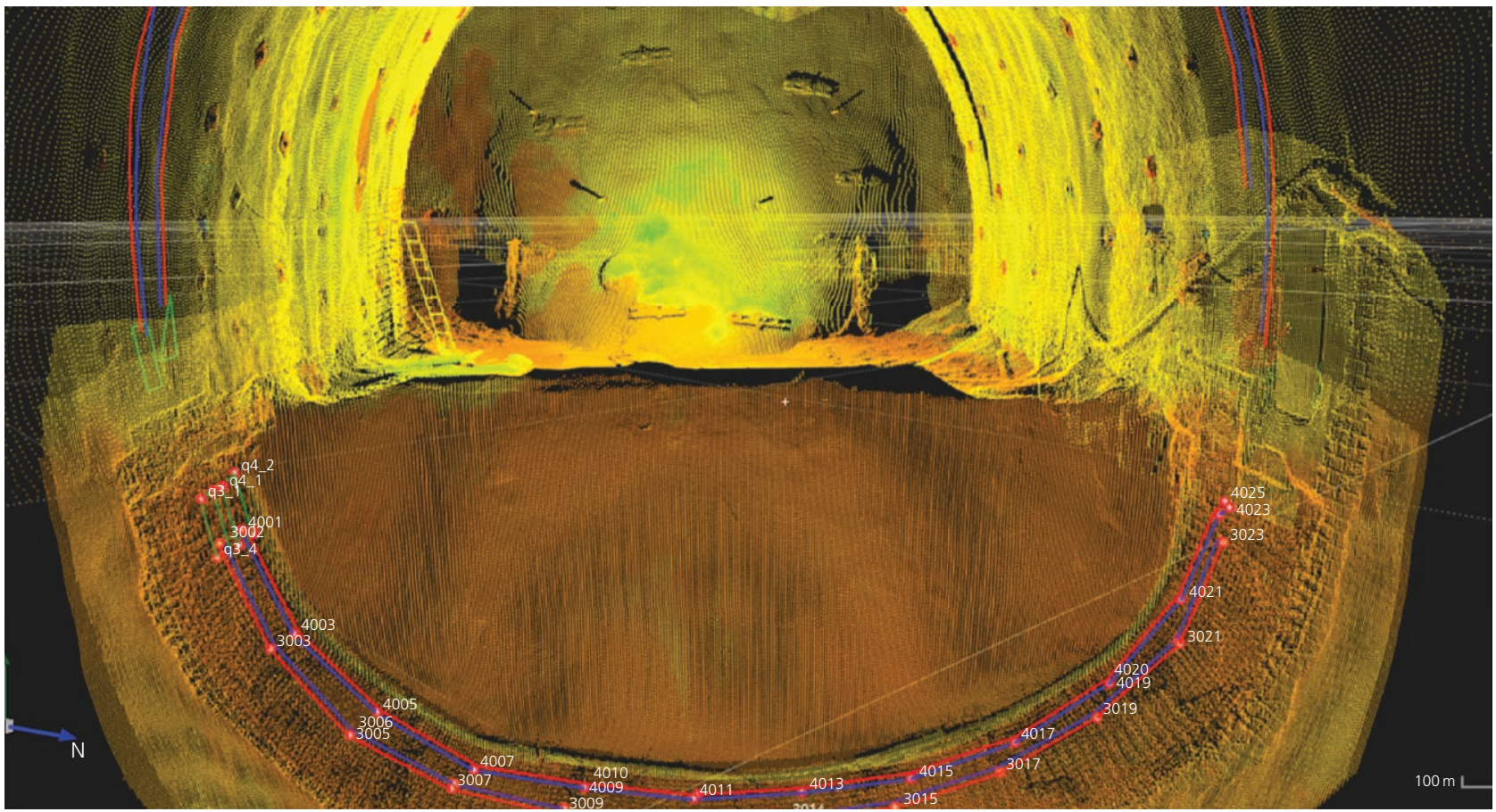

Figure 4. Point clouds of the tunnel cross-section and locations of the sensing cables in both shotcrete layers

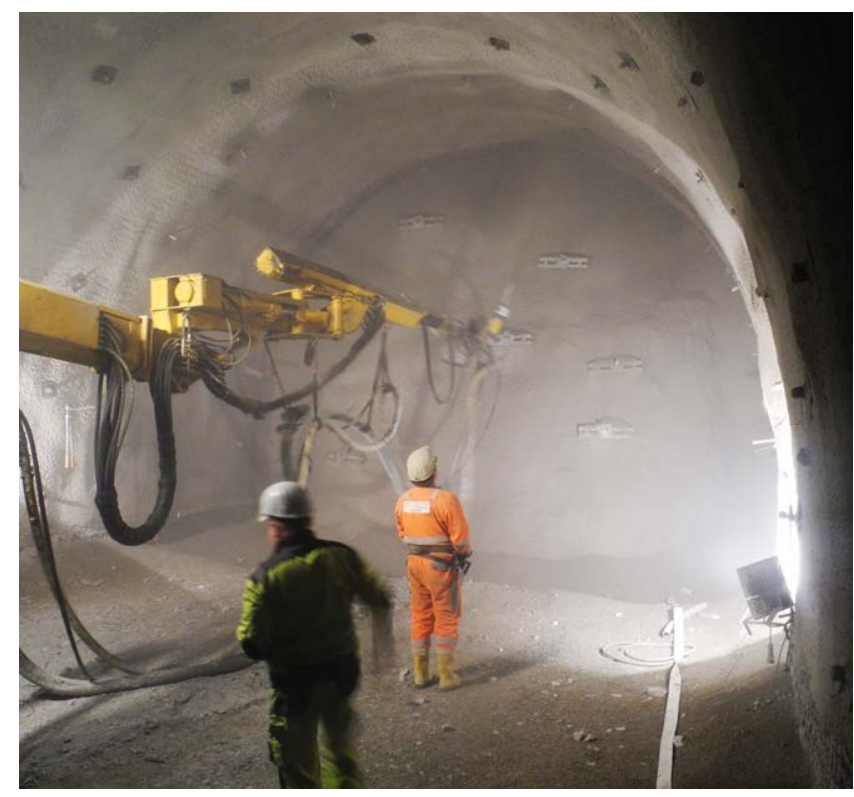

Figure 5. Spraying of the second layer of shotcrete of the top heading

\section{Göstritz access point}

\subsection{Shaft monitoring}

At the Göstritz intermediate access point, a complex construction was required to reach the planned altitude of the future railway tunnels. A more than $1 \mathrm{~km}$ long horizontal tunnel was driven from the surface into the mountain, at the end of which a massive cavern system was built to enable the construction of two approximately $240 \mathrm{~m}$ deep shafts and to host the logistics for work force, machine and material transport up and down the shafts. The complexity of this tunnel construction site is shown in Figure 8 and described in detail in the papers by Wagner et al. (2015) and Wieland et al. (2018).

Previous test boreholes revealed the geological circumstances in this area to be very challenging. Water intrusion is possible at various locations due to many geological fault sections. Critical, for instance, is the potential for an erosion of earth and rock material caused by water flow behind the shotcrete lining of the shafts. A geotechnical monitoring programme was set up to detect any degradation of the stability of the shaft walls at an early stage. Conventional 3D displacement measurements of the shaft walls with total stations are difficult due to very steep and almost vertical sightings. Total station measurements are, moreover, time consuming and hard to manage in shafts with water intrusion. They also interrupt the shaft-sinking process and interfere with the operation of the completed shafts. Total station targets, furthermore, become dirty within a short time in shafts and are problematic to clean. It was, therefore, decided that a distributed fibre-optic system embedded in the shotcrete linings of the shafts be used.

\subsection{Installation}

Based on the geological situation, five horizontal cross-sections with depths ranging from 177 to $229 \mathrm{~m}$ below the cavern were chosen for monitoring (Figure 9). Strain and temperature cables were installed in both layers of the shotcrete linings of every cross-section, in each 

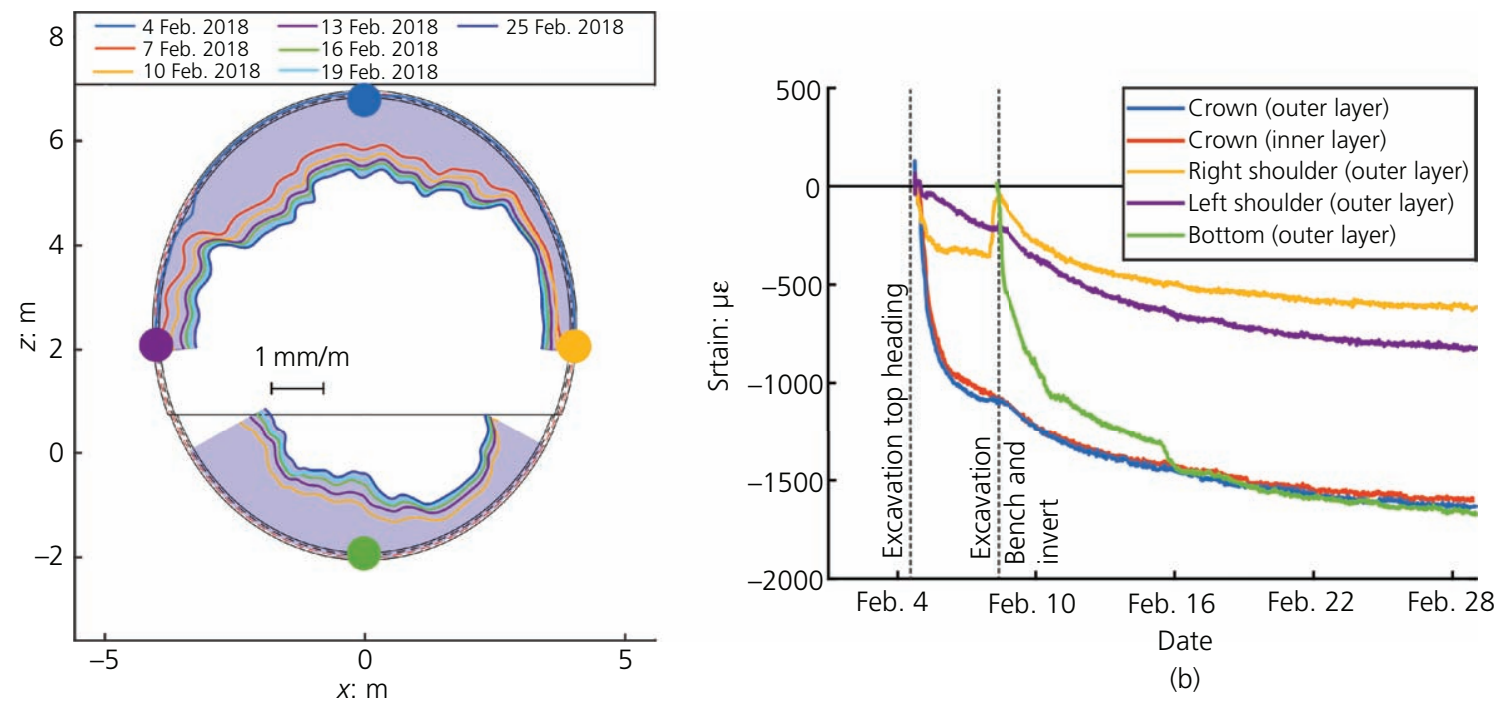

(a)

(b)

Figure 6. (a) Strain distribution along the outer layer; (b) strain development at five locations in February 2018

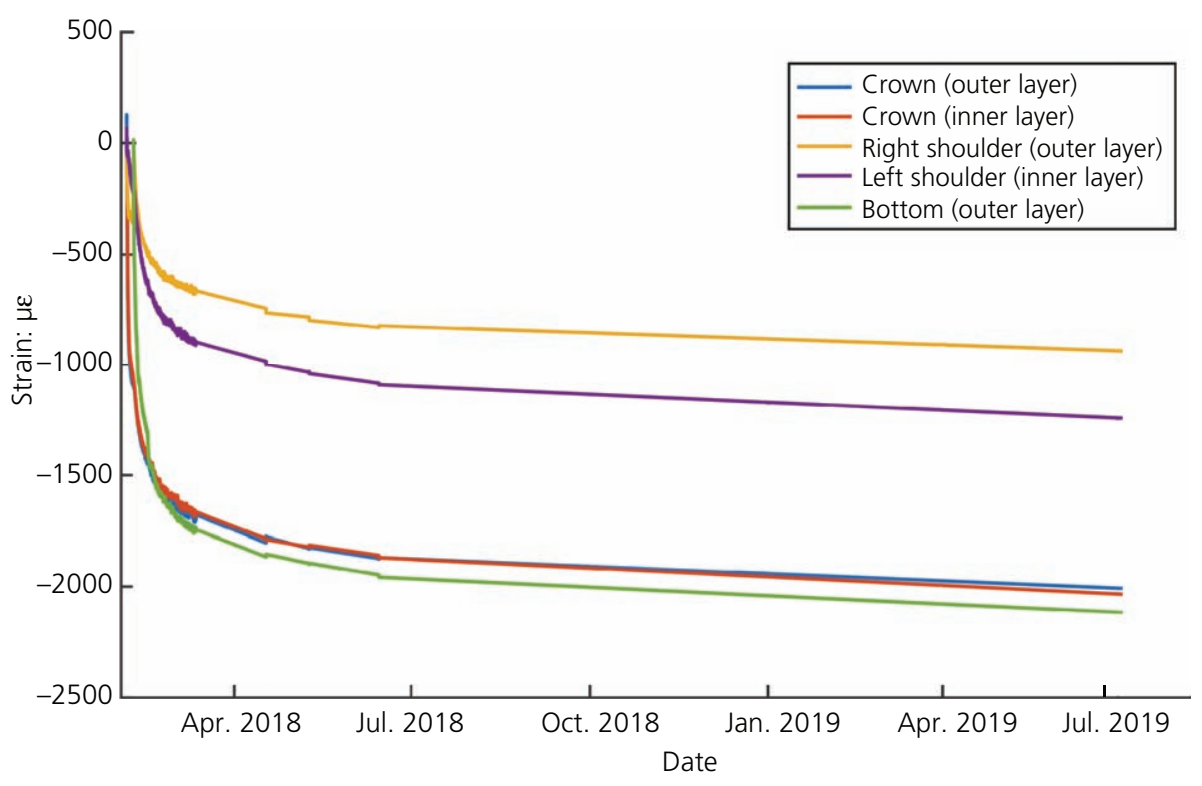

Figure 7. Long-term strain development of the tunnel lining

case configured as a loop with $70 \mathrm{~m}$ length $(35 \mathrm{~m}$ strain and temperature sensitive and $35 \mathrm{~m}$ only temperature sensitive).

A challenging aspect of this installation was the small working space in the shaft (Figure 10) due to the small diameter of $8 \mathrm{~m}$ and the amount of water, which constantly flowed along the shaft walls and dropped down. Waterproofing of the connection box and its surroundings was, hence, crucial during the installation process. The position of the fibre-optic sensing cables was again measured with a total station.
Each monitoring section has a connection box from which multifibre leading cables (Figure 9) establish the connection to a central measurement location (Figure 11) at the cavern at the top of the shafts. Measurements can, thus, be undertaken without any interference with the construction process.

Epoch-wise measurements are currently carried out every month with a fibrisTerre Brillouin instrument to gain a better understanding of the long-term behaviour of the shaft linings. If one of these measurements indicates significant changes, the set- 
Distributed fibre-optic sensing

applications at the Semmering Base

Tunnel, Austria

Lienhart, Buchmayer, Klug and Monsberger

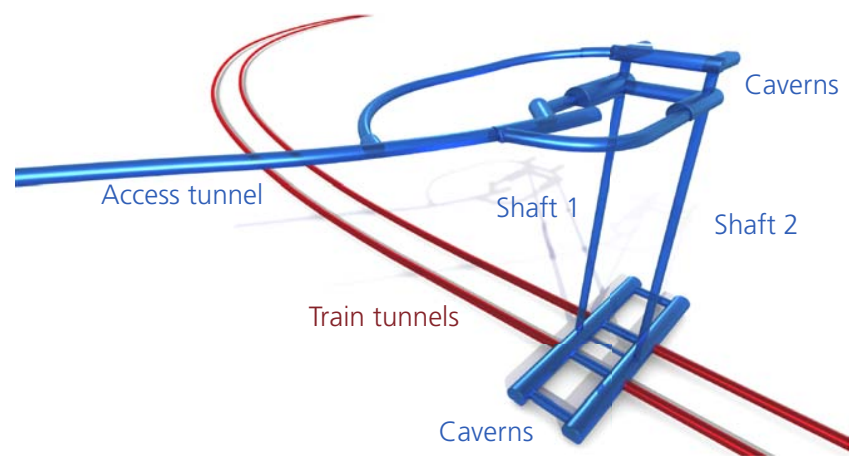

Figure 8. Access tunnel, caverns and shafts at the Göstritz access point of the SBT (after Wieland et al., 2018)

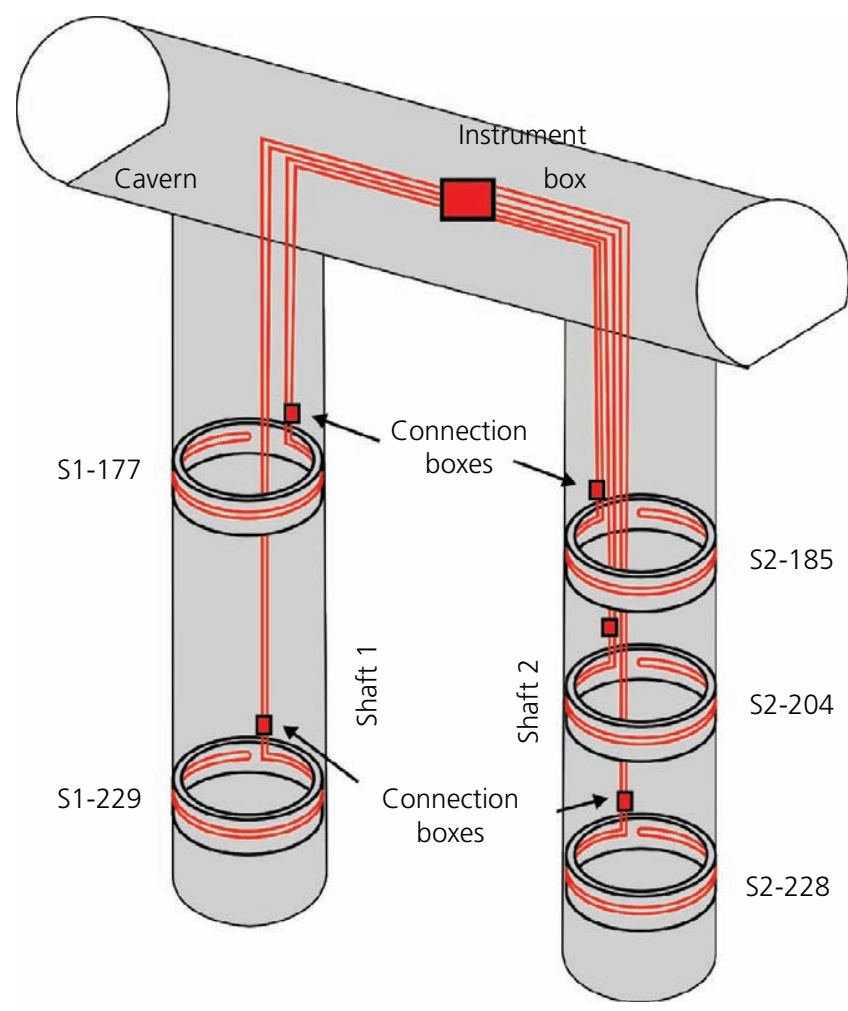

Figure 9. Layout (not to scale) of the distributed fibre-optic measurement system at the Göstritz access point

up is in place to enable a switch from epoch-wise measurements to continuous measurements.

\subsection{Results}

The Brillouin spectrum was recorded at every measurement epoch with a spatial resolution of $0.5 \mathrm{~m}$ and a sampling interval of $0.05 \mathrm{~m}$. The spectrum of one cross-section is shown in Figure 12 . As mentioned earlier, about $70 \mathrm{~m}$ of sensing cables were installed in every shotcrete layer. The different base frequencies of the different cable types (strain and temperature) are clearly visible.

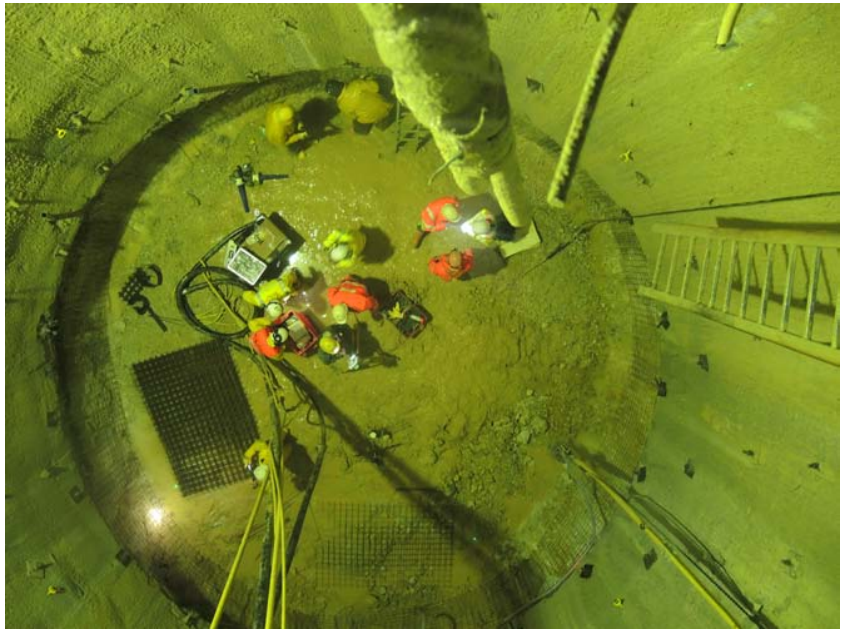

Figure 10. Vertical view down the shaft during construction at Göstritz

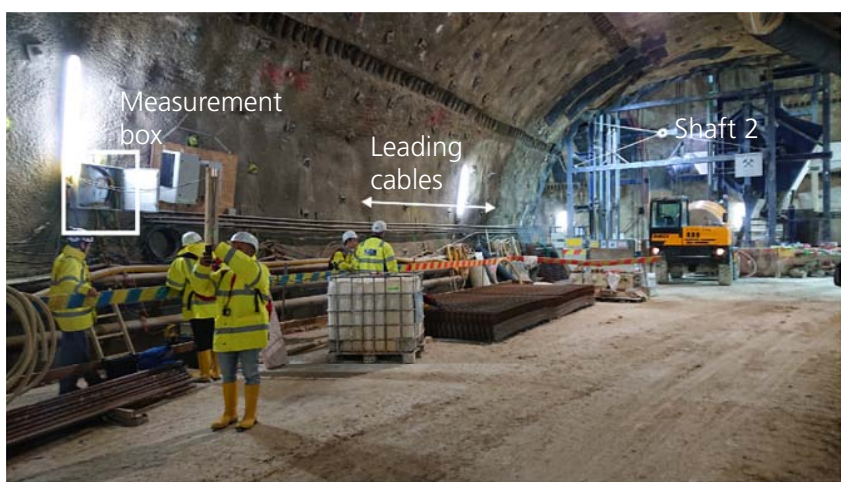

Figure 11. Cavern at Göstritz

Greater variation in the Brillouin frequencies along the strain cables than along the temperature cables can, furthermore, be seen due to the strain development of the lining.

In the processing step, the temperature impact on the strainsensing cables was numerically compensated for using the data from the corresponding positions of the temperature cable. To support data interpretation, it is beneficial to display the strain results along the shaft lining. This is exemplified using the S2-228 strain values in Figure 13, which shows the strain changes with respect to the zero measurement taken on 21 August 2018. It can be seen that the strain change is not homogenous along the entire cross-section: almost no strain changes occur, for example, at the 12 o'clock position. A reduction in the velocity of the strain changes is, furthermore, noteworthy. Within the 3 weeks between 27 August 2018 and 19 September 2018, the strain decreases significantly more than during the 3 weeks between 19 September 2018 and 11 October 2018. Overall, a maximum strain decrease of about $1000 \mu \mathrm{m} / \mathrm{m}$ was observed for this cross-section. 


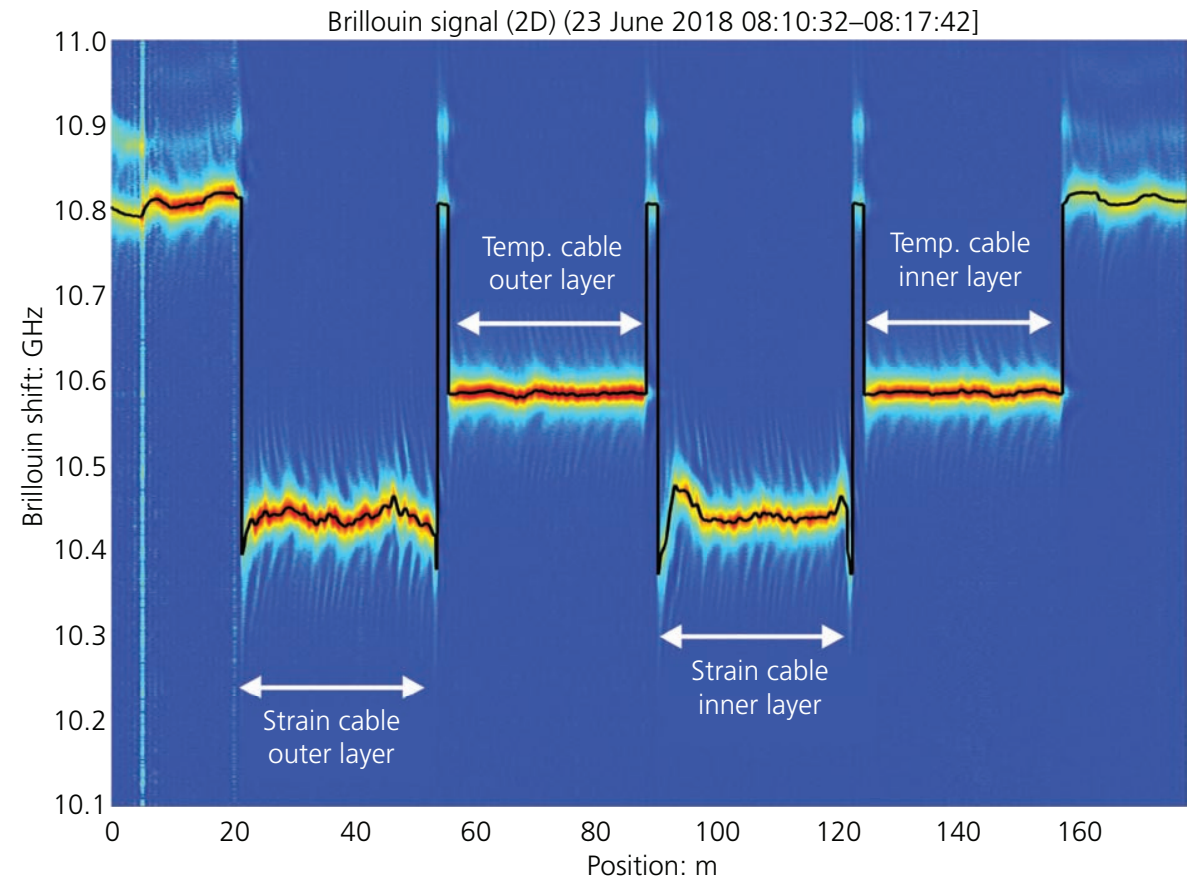

Figure 12. Brillouin spectrum of cross-section S2-185 recorded on 23 June 2018

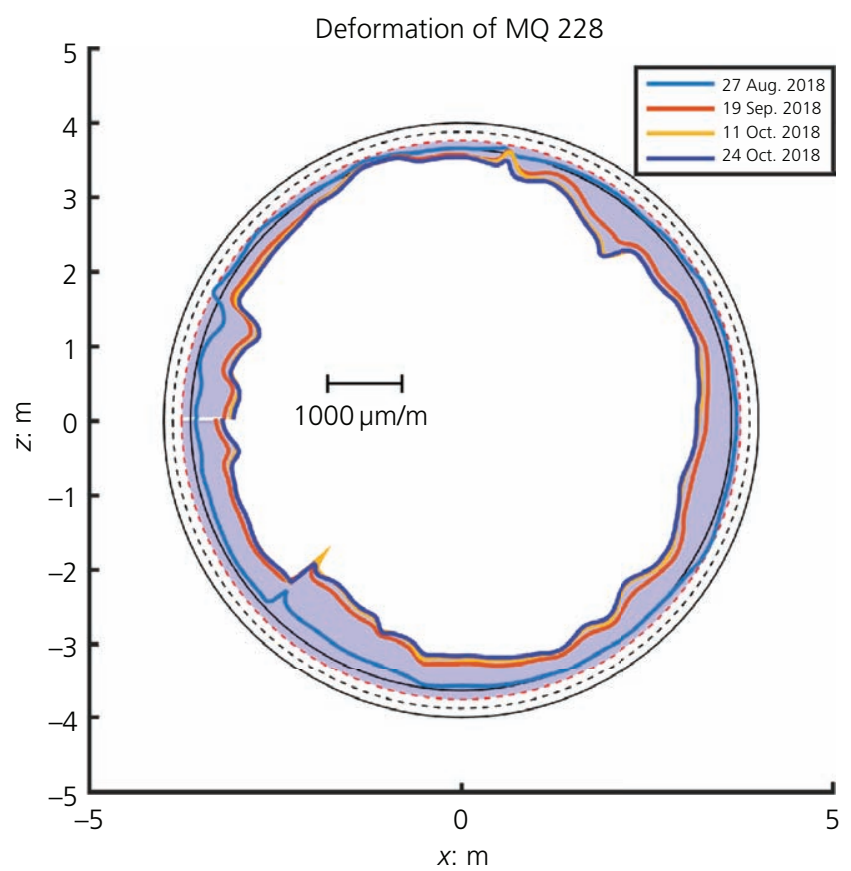

Figure 13. Strain distribution along the inner layer of the shotcrete lining of section S2-228 at different dates with respect to the zero measurement on 21 August 2018

So far, no degradation of the stability of the shaft walls was observed and tunnel operation could be proceeded in a safe state. The installed measurement system is intended to be used for the next 8 years until tunnel construction is completed and after which the shafts will be refilled. Reliable operation of distributed fibreoptic systems for several years or even longer was already previously demonstrated at the SBT Fröschnitzgraben access point.

\section{Fröschnitzgraben access point}

\subsection{Longsgraben disposal site}

A legal environmental requirement for the construction of the SBT was that most of the excavation material must remain in the Semmering mountain area. The Longsgraben valley was selected as a central disposal site to enable compliance. Material from the Fröschnitzgraben access point (Nipitsch and Pacher, 2017) is transported to the disposal site with a conveyor belt, while material from the other intermediate access points is trucked there.

To render the inhabited mountain valley a suitable landfill area, trees had to be felled and the stream at the bottom of the valley relocated to a higher level, which will form the new valley bottom following complete filling of the disposal site with the tunnel excavation material (Figure 14). More detailed information concerning these preliminary works for the SBT can be found in the paper by Schuller et al. (2014).

The challenge in this case was to build a stable supporting structure for the new riverbed while minimising capacity loss at the disposal site. To achieve this, a reinforced earth structure was selected. The slopes of the realised construction have an angle of up to $75^{\circ}$ and a height of up to $25 \mathrm{~m}$. To assess the stability of the structure, deformations are measured to bi-reflex targets on the 
Distributed fibre-optic sensing

applications at the Semmering Base

Tunnel, Austria

Lienhart, Buchmayer, Klug and Monsberger

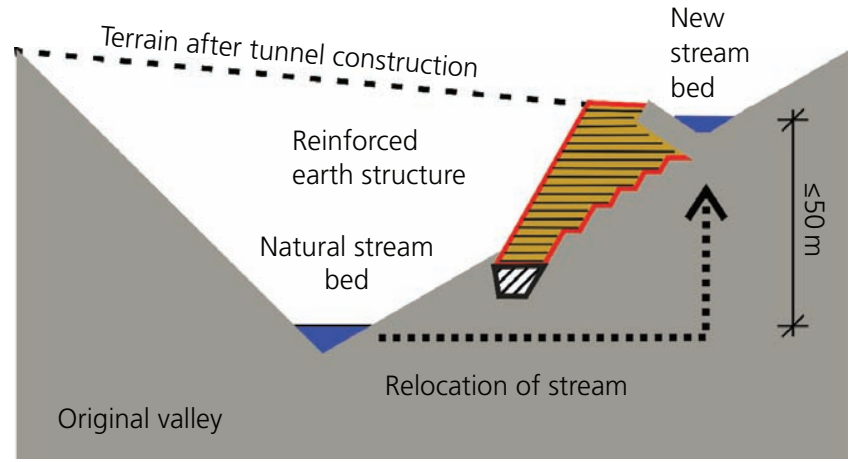

Figure 14. Relocation of a stream using a reinforced earth structure in the Longsgraben valley

surface of the structure. These measurements are, however, sensitive only to surface displacements and do not provide information about internal strain distribution. Conventional geodetic measurements were, thus, complemented with internal DFOS measurements. The aim of the fibre-optic measurements was to obtain information about the internal strain distribution to assess the utilisation grade of the geo-grids. The required strain measurement accuracy for this project was $100 \mu \varepsilon$.

\subsection{Installation within the reinforced earth structure}

To obtain a suitable spatial resolution, four cross-sections were equipped at different heights with fibre-optic sensing cables. At each section, the sensing cables were directly connected to the geo-grids with specially designed and tested anchors. A loop-configured sensing system was chosen. In the forward loop of each level, the sensing cable was pre-strained to also capture negative strain, whereas the back-loop was laid without tensioning and was thus sensitive only to temperature changes. All sensing cables were connected to one measurement loop with a length of about $2.5 \mathrm{~km}$, which can be measured from a single monitoring station (Figure 15).
Figure 16 shows the disposal site photographed from the same location in 2016 and 2019. In 2016, the landfill operation just started, whereas by the end of 2019 , the disposal volume was already filled up to about $75 \%$.

\subsection{Long-term results}

Weekly measurements were carried out during the September 2013 construction phase to capture early strain evolution in the geo-grids. During this critical phase, clear actions were defined by a safety-management plan in case that strain values would exceed threshold values. One of the defined actions was to attach backanchored concrete beams at sections with excessive strain. However, threshold values were not exceeded, and thus, no actions had to be initiated. After construction, monitoring was continued with quarterly measurements and is still ongoing. All measurements were performed with a Brillouin instrument from fibrisTerre. Moser et al. (2016) already described strain development within the first year. In this paper, the authors focus on the long-term strain evolution. Three distinct phases can be identified in Figure 17 where the strain development of level 2 of cross-section 1 is shown. Phase A corresponds to the construction of the retaining structure in 2013. The load increased sequentially as more and more earth layers are placed on the top of the monitoring level. The extra weight induced positive strain of up to $0.4 \%$, where the highest strains were observed in the monitoring section closest to the surface. After construction, creeping effects occurred, indicated as phases B in Figure 17. This behaviour was expected; however, in 2017, a sudden jump in all strain readings occurred.

This sudden increase of the strain was investigated in more details. A review of the activities in the landfill area revealed that the access ramp of the reinforced earth structure was modified at the time of the jump (Figure 18). In order to transport the disposal material with larger dumpers, the road was modified in the curved section. The widening of the road was realised by an earth fill,

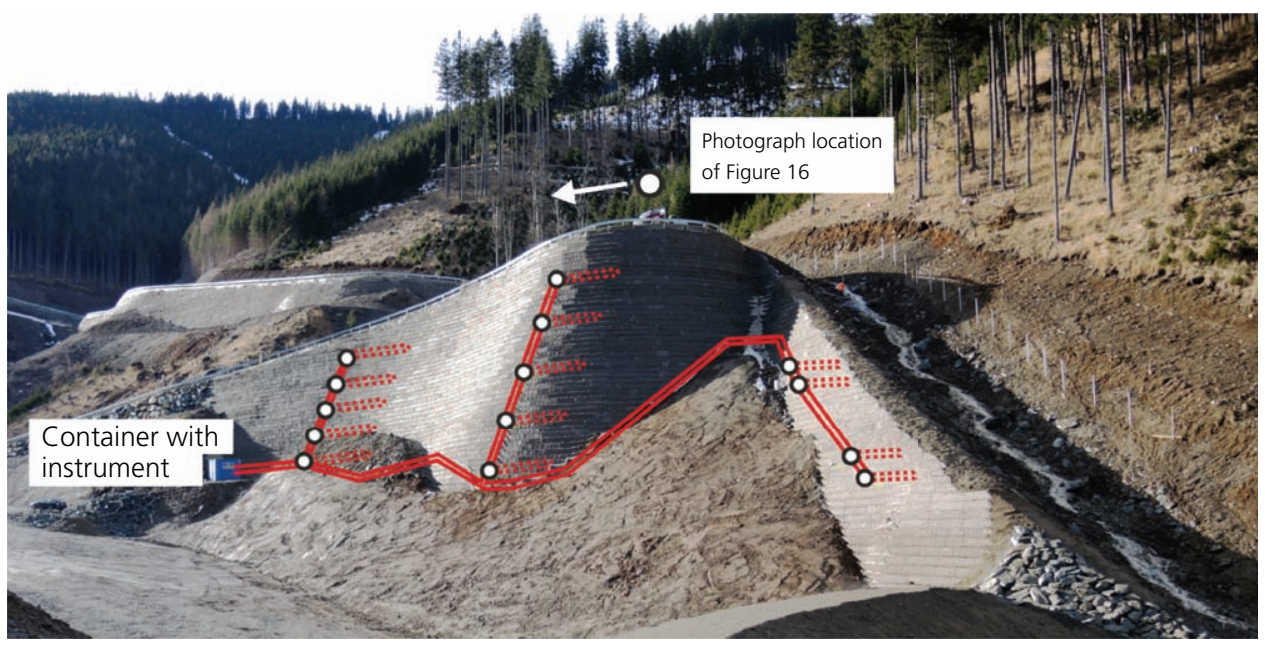

Figure 15. Fibre-optic measurement loop at the reinforced earth structure in the Longsgraben valley 


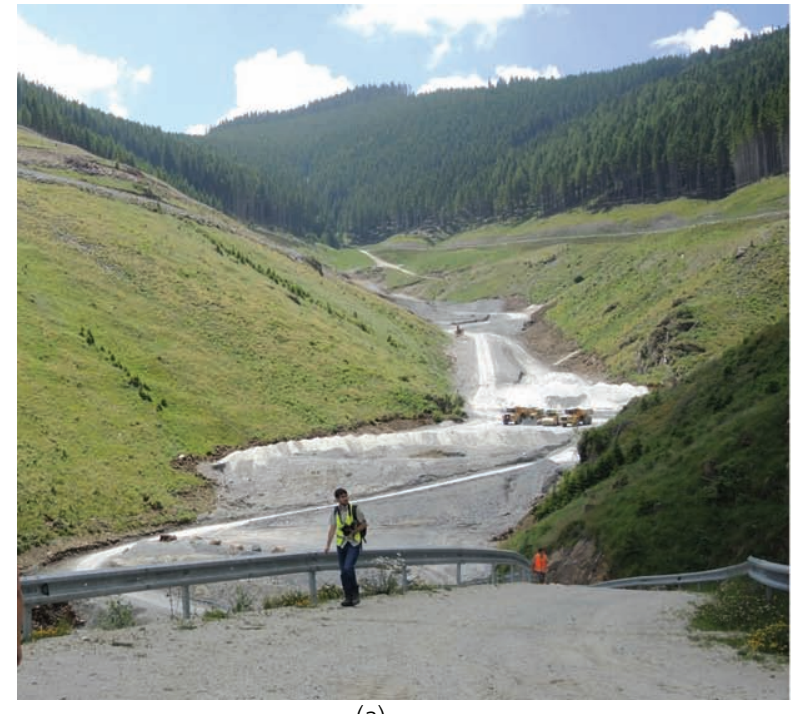

(a)

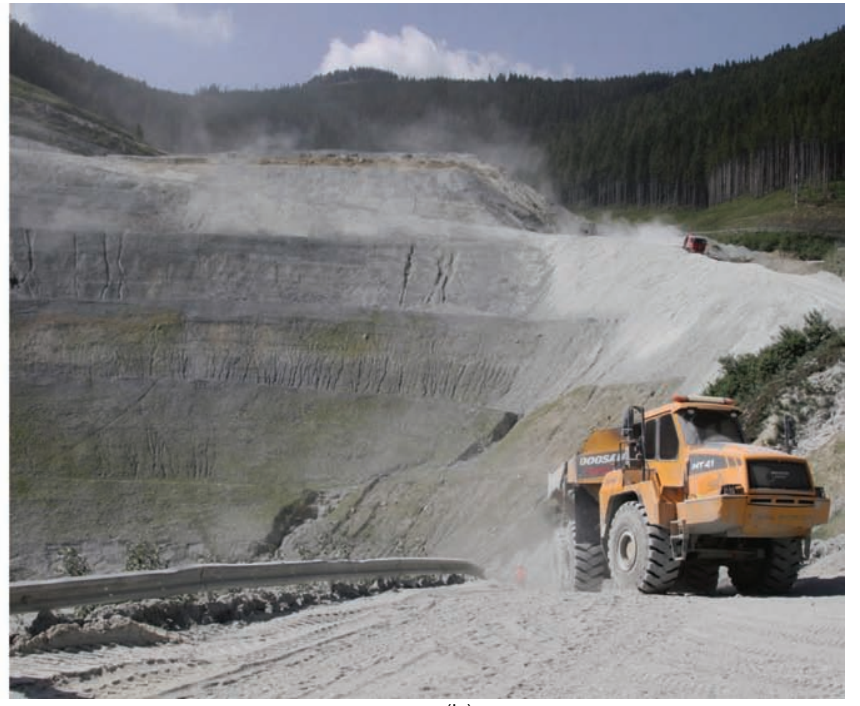

(b)

Figure 16. View of the landfill area from the same location on (a) 23 June 2016 and (b) 13 June 2019
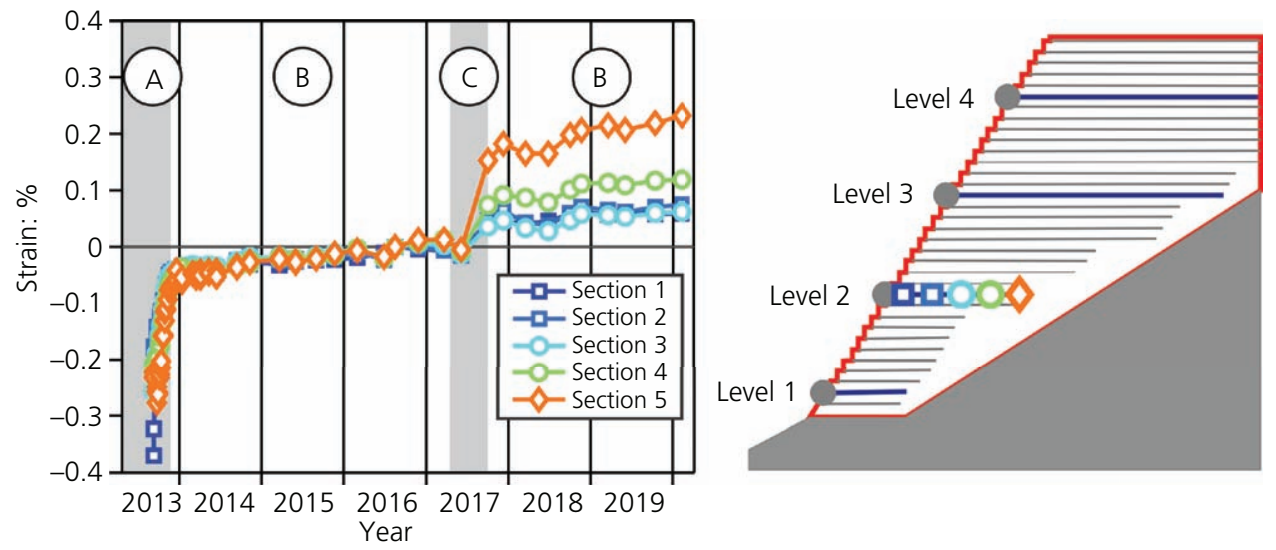

Figure 17. (a) Strain evolution of the geo-grid within the reinforced earth structure of level 2 of cross-section 1; (b) location of sections within level 2

which caused extra weight and induced the sudden increase of strain. After this event, the deformations went back to a small creeping trend. This highlights the importance of long-term measurements, which can depict initial deformations after construction, long-term creep and single events. As a consequence, this section is now observed in greater detail in order to be able to react with a sufficient lead time in case the strain development does not stabilise.

\section{Grautschenhof access point}

6.1 Pipeline monitoring

So far, the described DFOS installations generated epoch-wise measurements or continuous measurements limited to a period of several weeks. However, the SBT construction also contains a continuous DFOS monitoring system with automated alarming at the Grautschenhof access point. Space is very limited at the final access point since, above ground, the entire construction site for the two tunnel tubes is sandwiched between a highway and a mountain slope. Access to the tunnel tubes is achieved by way of two $100 \mathrm{~m}$ deep shafts. A particular challenge was posed by a corridor of three gas pipelines that cross the construction area over a distance of $320 \mathrm{~m}$. One of these is the main feed line for the region of Styria, and uninterrupted operation is, thus, crucial. An overview of the complex situation at this access point is shown in Figure 19 and also described in the paper by Klais et al. (2017). To enable immediate detection of any deleterious impacts on the pipelines, it was decided that a fully automated permanent fibre-optic monitoring system with an automated alarm be installed. 
Smart Infrastructure and Construction

Volume 172 Issue 4
Distributed fibre-optic sensing

applications at the Semmering Base

Tunnel, Austria

Lienhart, Buchmayer, Klug and Monsberger

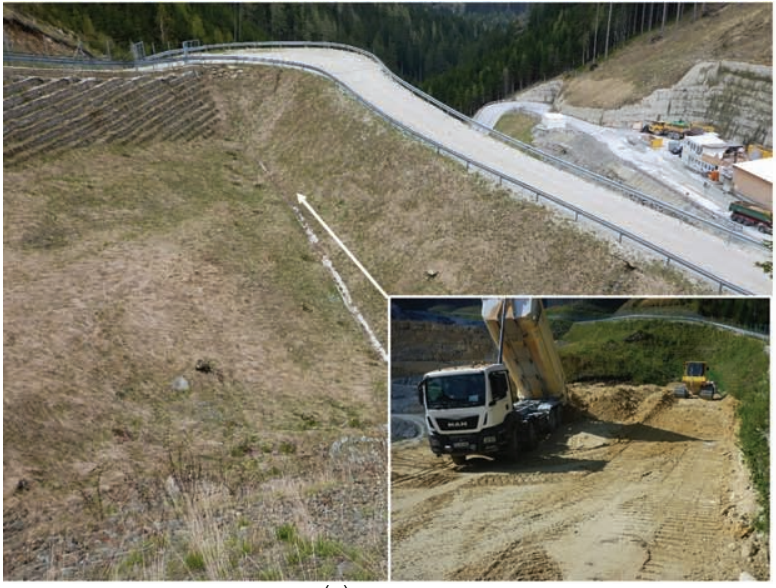

(a)

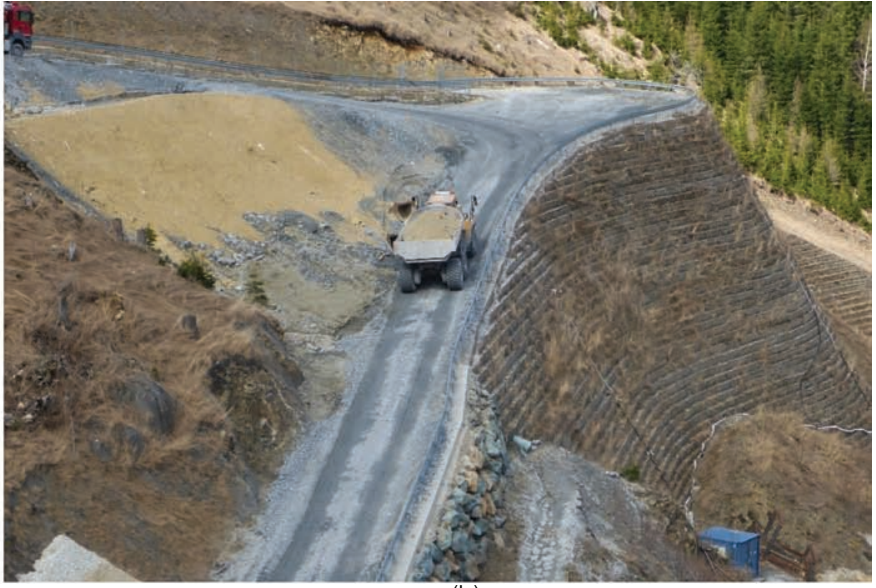

(b)

Figure 18. Photographs of the (a) initial road, modification works (insert) and (b) current view

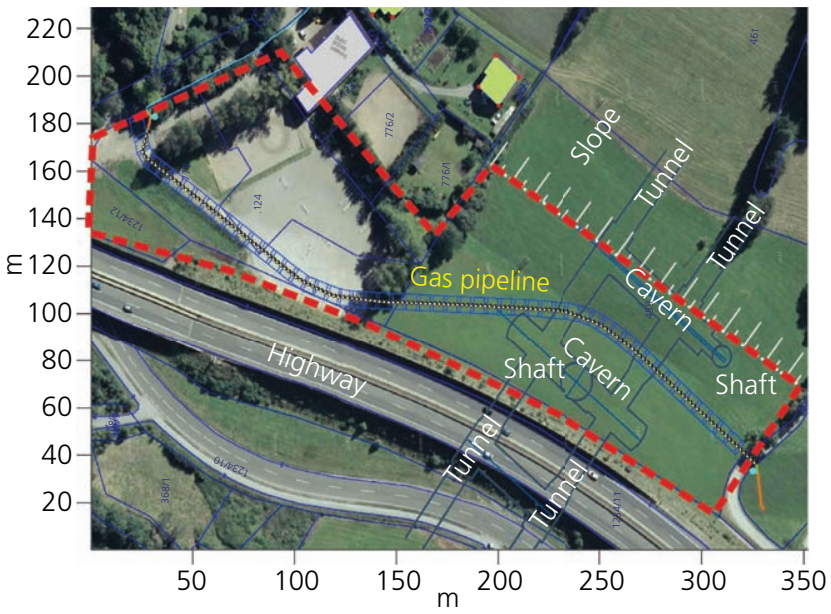

Figure 19. Construction site Grautschenhof (red) with gas pipeline corridor

\subsection{Installation}

The three pipelines originally traversed the construction area along different paths. To provide sufficient space for the two access shafts, the two smaller pipelines $(0.15$ and $0.30 \mathrm{~m}$ diameters) were placed next to the larger $(0.80 \mathrm{~m}$ dia.) pipeline in order to locate all three pipelines within a single corridor. The open trench during the relocation can be seen in Figure 20.

During the relocation process, three DFOS cables were mounted on one of the pipelines. These cables were glued along the entire pipeline length at the positions 9, 12 and 3 o'clock as shown in Figure 21. This configuration enables calculations of both the average longitudinal strain and horizontal and vertical curvatures. A separate loose cable was, furthermore, installed parallel to the pipeline to enable temperature compensation. For the measurements, all cables were connected to create a loop that was

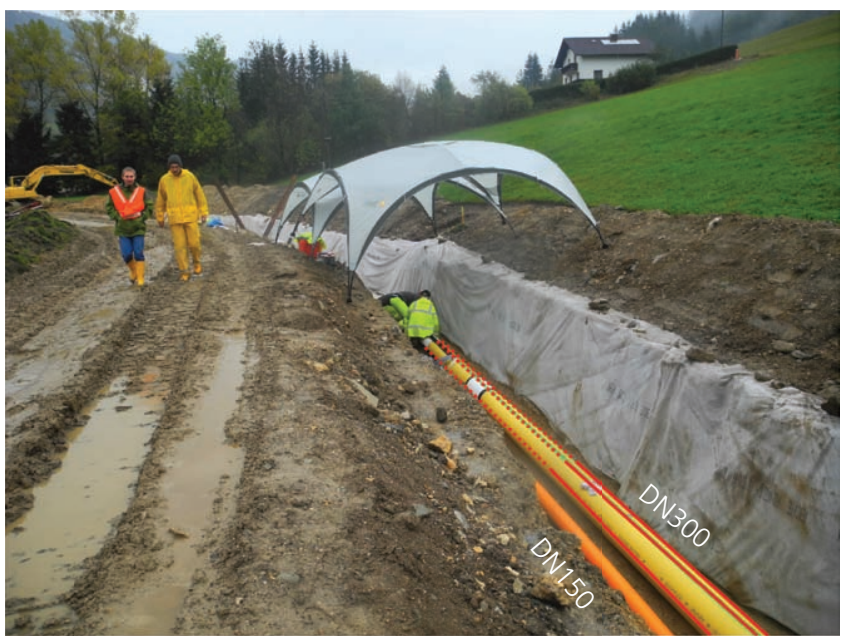

Figure 20. Relocation of the pipelines at the Grautschenhof construction site

extended with leading cables to a nearby building where the instrument rack with a combined BOTDA and BOTDR instrument from Omnisens is located. This significantly improves system robustness since, in the event of fibre breakage, the measurements can be changed from the loop set-up (BOTDA mode) to a single-ended configuration (BOTDR mode).

To distribute the construction traffic load, the three pipelines were covered with $6 \mathrm{~m}$ wide concrete load distribution plates (Figure 22(a)). Figure 22(b) shows the area during construction of the $100 \mathrm{~m}$ deep shafts. Automated surface-based measurements for example, with a total station - are clearly impossible due to the many obstacles that would obstruct the line of sight. The installed subterranean distributed fibre-optic measurement system is, thus, the only solution able to monitor permanently the pipelines without interfering with construction work. 

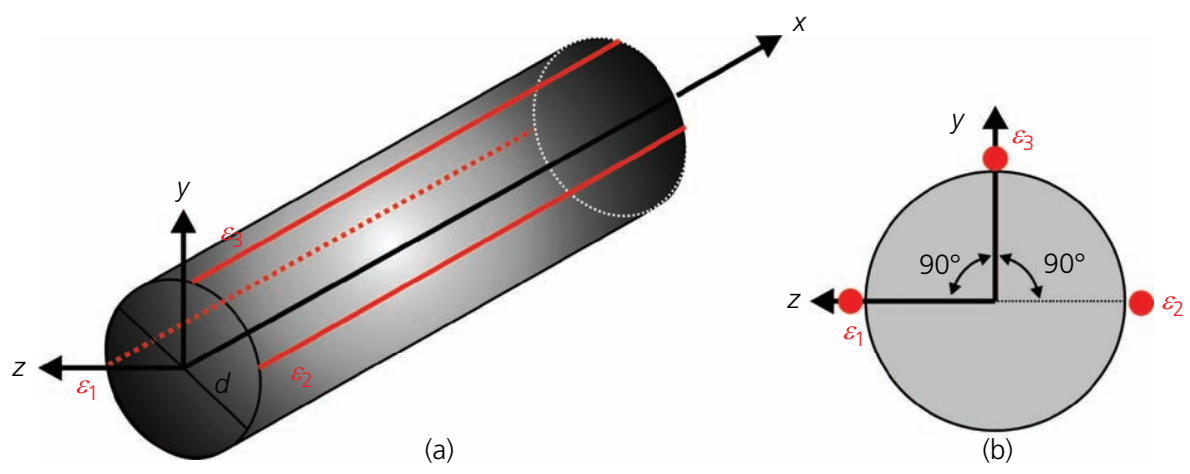

Figure 21. Location of the sensing cables on the pipeline at Grautschenhof: (a) perspective view; (b) cross section

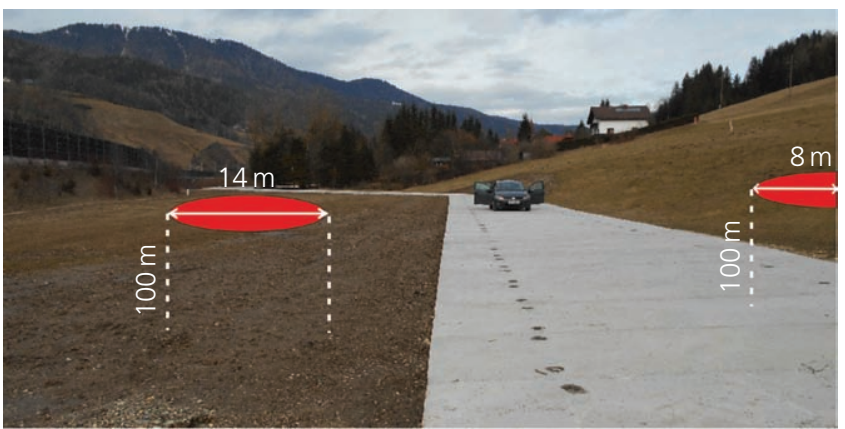

(a)

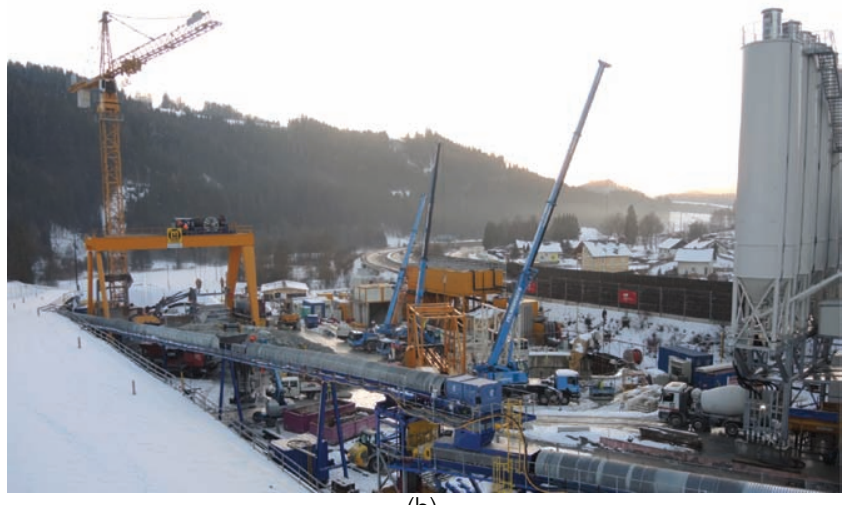

(b)

Figure 22. Construction site after installation of the fibre-optic sensing cables (a) in 2016 and (b) in winter 2018

\subsection{Results}

The monitoring system has been on-line since July 2016 and is currently configured to measure the fibre loop every hour at a spatial resolution of $1 \mathrm{~m}$. To reduce measurement noise, time averages over $6 \mathrm{~h}$ and spatial averages over $2 \mathrm{~m}$ are calculated. Temperature compensation and strain and curvature calculations are performed with the authors' own integrated algorithms. The results are compared with the warning and alarming threshold values provided by an external consultant. For longitudinal strain, these thresholds are $230 \mu \mathrm{m} / \mathrm{m}$ for warning and $460 \mu \mathrm{m} / \mathrm{m}$ for alarming. If these limits are exceeded, e-mail notification is automatically started and
Section: 2; epoch: Jul. 2016 to Jan. 2019 Left sensor

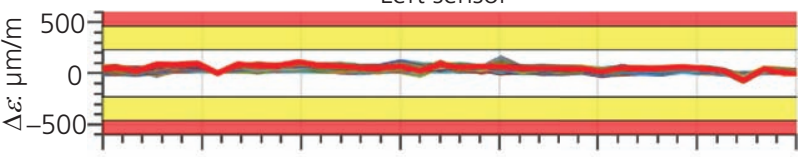

Top sensor

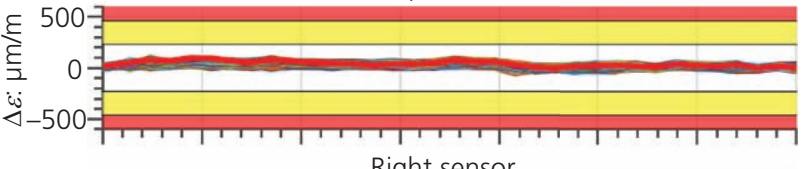

Right sensor

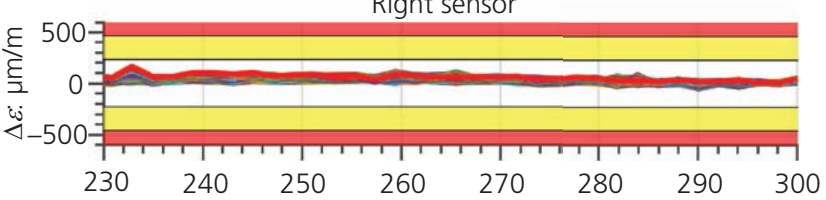

Figure 23. Measured strain values of section 2 since the start of operation

countermeasures are initiated in accordance with the safety plan. Figure 23 shows the temperature-corrected strains for each sensor line of section 2. The length of this section, which is located at the entrance area of the construction site, is about $70 \mathrm{~m}$. After more than 2.5 years of permanent measurements, the strain values lie within a range of $\pm 200 \mu \mathrm{m} / \mathrm{m}$. The issuing of warning or alarming values for this section has, thus, so far not been necessary, unlike other sections as discussed by Klais et al. (2017).

\section{Summary and outlook}

This paper describes different DFOS installations for a large tunnel project. Overall, about $6.5 \mathrm{~km}$ of sensing cables were installed at various construction locations. While the monitored objects differ, the main goals are the same at every access point. The measurements must, firstly, not interfere with the construction process since any delay to a tunnelling project is costly. Secondly, the measurements must provide detailed information about the internal behaviour of the object without any information gaps. Thirdly, the measurement systems must be designed to be operated over many decades. Last but not least, the measurements must provide reliable information 
under harsh conditions and any temperature impact must be corrected. All of the installations presented in this paper are integrated in the safety-management plans with defined actions in case that threshold values are exceeded.

The authors have demonstrated the fulfilment of all of the objectives and shown that the installed monitoring systems do indeed increase safety, enable more efficient construction and can contribute to condition-based maintenance during the 150-year operational lifetime of this tunnel.

At the Fröschnitzgraben intermediate access point, two TBMs are currently starting operations $400 \mathrm{~m}$ below the surface. These machines place precast concrete segments to create the tunnel lining. Equipment of these tunnel lining segments with DFOS has already been shown by the authors' group at the Koralmtunnel (Monsberger and Lienhart, 2017; Monsberger et al., 2018b) and by Soga et al. (2015). This approach is a potential solution for short- and long-term monitoring of precast tunnel lining rings.

\section{Acknowledgements}

The authors would like to thank all project partners for their support and funding of the monitoring projects. Special thanks go to the Austrian Federal Railways (ÖBB-Infra) - namely, Michaela Haberler-Weber, Johannes Fleckl-Ernst, Tobias Schachinger, Frank Klais, Petra Wolf and the project leader of the Semmering Base Tunnel, Gerhard Gobiet. Furthermore, the authors appreciate the collaboration with their other partners, the Institute of Rock Mechanics and Tunnelling of Graz University of Technology (Wulf Schubert and Michael Henzinger), Insitu (Hartmut Schuller), HBM (Walter Weilinger and Raimund Stefaner), Chris Wrighton, Asfinag Bau Management GmbH (Michael Steiner) and the Federal Ministry for Transport, Innovation and Technology, who all gave valuable input to the different projects, the data interpretation and result communication.

\section{REFERENCES}

De Battista N, Elshafie M, Soga K et al. (2015) Strain monitoring using embedded fibre optic sensors in a sprayed concrete tunnel lining during the excavation of cross-passages. In Proceedings of the 7th International Conference on Structural Health Monitoring of Intelligent Infrastructure - SHMII, Turin, Italy, pp. 47-56.

Gobiet G, Nipitsch G and Wagner OK (2017) The Semmering Base Tunnel - special challenges in construction. Geomechanics and Tunnelling 10(3): 291-297, https://doi.org/10.1002/geot.201700008.

Hartog AH (2018) An Introduction to Distributed Optical Fibre Sensors. CRC Press, Boca Raton, FL, USA.

Henzinger R, Schachinger T, Lienhart W et al. (2018) Fibre-optic supported measurement methods for monitoring rock pressure. Geomechanics and Tunnelling 11(3): 251-263, https://doi.org/10.1002/ geot.201800015.

Klais F, Wolf P and Lienhart W (2017) The Grautschenhof contract construction of an intermediate access under complex local conditions. Geomechanics and Tunnelling 10(6): 686-693, https://doi.org/10. 1002/geot.201700052.

Krohn D, McDougall T and Mendez A (2014) Fiber Optic Sensors: Fundamentals and Applications, 4th edn. SPIE Press, Bellingham, WA, USA.
Monsberger CM and Lienhart W (2017) In-situ deformation monitoring of tunnel segments using high-resolution distributed fibre optic sensing. Proceedings of the 8th International Conference on Structural Health Monitoring of Intelligent Infrastructure - SHMII-8, Brisbane, Australia, RS1-9.

Monsberger CM, Lienhart W, Kluckner A, Wagner L and Schubert W (2018a) Continuous strain measurements in a shotcrete tunnel lining using distributed fiber optic sensing. Proceedings of 9th European Workshop on Structural Health Monitoring (EWSHM), Manchester, UK

Monsberger CM, Lienhart W and Moritz B (2018b) In-situ assessment of strain behaviour inside tunnel linings using distributed fibre optic sensors. Geomechanics and Tunnelling 11(6): 701-709, https://doi.org/ 10.1002/geot.201800050.

Moser F, Lienhart W, Woschitz H and Schuller H (2016) Long-term monitoring of reinforced earth structures using distributed fiber optic sensing. Journal of Civil Structural Health Monitoring 6(3): 321-327, https://doi.org/10.1007/s13349-016-0172-9.

Nipitsch G and Pacher W (2017) The Fröschnitzgraben contract challenges in shaft sinking, construction logistics and landfill. Geomechanics and Tunnelling 10(6): 678-685, https://doi.org/10. 1002/geot.201700053.

OeGG (Austrian Society for Geomechanics) (2010) NATM - the Austrian Practice of Conventional Tunnelling. OeGG, Salzburg, Austria.

OeGG (2014) Geotechnical Monitoring in Conventional Tunnelling OeGG, Salzburg, Austria.

Schuller H, Riepler F and Schachinger T (2014) Preliminary works for the new Semmering Base Tunnel - geotechnical monitoring of slope stabilization measures and earth retaining structures. Geomechanics and Tunnelling 7(4): 339-352, https://doi.org/10.1002/geot. 201400028.

Soga K, Kwan V, Pelecanos L et al. (2015) The role of distributed sensing in understanding the engineering performance of geotechnical structures. In Geotechnical Engineering for Infrastructure and Development: XVI European Conference on Soil Mechanics and Geotechnical Engineering (Winter MG, Smith DM, Eldred PJL and Toll DG (eds)). ICE Publishing, London, UK, pp. 1-48.

Wagner OK, Haas D, Druckfeuchter H and Schachinger T (2015) The challenges of contract SBT1.1 'Tunnel Gloggnitz'. Geomechanics and Tunnelling 8(6): 554-567, https://doi.org/10.1002/geot.201500038.

Wagner L, Kluckner A, Monsberger CM et al. (2020) Direct and distributed strain measurements inside a shotcrete lining: concept and realisation. Rock Mechanics and Rock Engineering 53: 641-652, https://doi.org/10.1007/s00603-019-01923-4.

Wieland G, Prall K, Lenz G, Schachinger T and Gobiet G (2018) Semmering Base Tunnel - design and construction of the shaft head caverns under difficult conditions. Geomechanics and Tunnelling 11(5): 462-470, https://doi.org/10.1002/geot.201800040.

\section{How can you contribute?}

To discuss this paper, please email up to 500 words to the editor at journals@ice.org.uk. Your contribution will be forwarded to the author(s) for a reply and, if considered appropriate by the editorial board, it will be published as discussion in a future issue of the journal.

Proceedings journals rely entirely on contributions from the civil engineering profession (and allied disciplines). Information about how to submit your paper online is available at www.icevirtuallibrary.com/page/authors, where you will also find detailed author guidelines. 